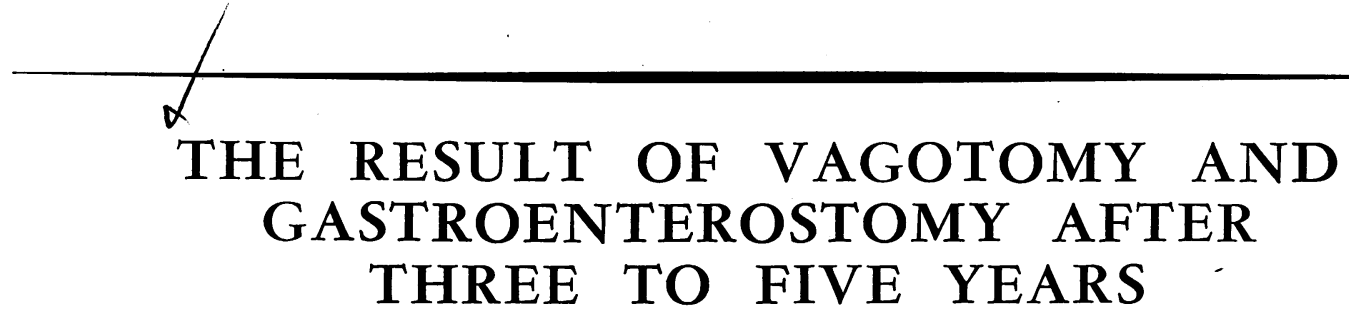

\author{
By B. V. McEvedy, F.R.C.S. \\ Senior Registrar, University College Hospital, London \\ and G. K. KiRkLand, M.B., Ch.B., D.P.H. \\ Assistant Surgeon, Oldham Royal Infirmary and Ancoats Hospital
}

It is only I I years since Lester Dragstedt reintroduced vagal section in the treatment of peptic ulcers, yet in this short period, after attaining a popularity almost equal to that of partial gastrectomy, the operation has fallen into disrepute and is now rarely performed. Despite the many failures large numbers of patients have been cured by vagotomy although the different factors producing success or failure have not been adequately elucidated. In the three years prior to 1948 it was shown that vagotomy was contra-indicated for -gastric ulcers and that for duodenal ulcers a gastroenterostomy must also be performed to overcome the gastric stasis produced by paralysis of the stomach. This paper sets out the results of one surgical team between 1948 and 195 I, during which period all duodenal ulcers were treated by vagal section with, in all cases, the vagotomy accompanied by a gastroenterostomy.

The technique of the operation was essentially that put forward by Dragstedt (1947). The gastroenterostomy was placed within 2 in. of the pylorus as on barium meal, this was found to be the most dependent part of the stomach; with the classical type of gastroenterostomy on an atonic stomach a pouch is formed between the stoma and the pylorus in which food is retained for long periods. All the operations were performed under local anaesthesia as this was thought to be the safest of all anaesthetics.

\section{The Follow-up Series}

In this paper are considered 184 cases of peptic ulcers operated upon by the late Peter G. McEvedy and one of the writers (G.K.K.). The operations were performed between 1948 and July I95 I, so that all the patients have been followed for over three years and some for more than six years. The follow-up has been largely by questionnaire, but nearly a quarter of the cases have been seen personally; while questionnaire follow-up has been criticized as inaccurate, it is of interest that no case seen was worse than the questionnaire had implied while several were better. The series consisted of 175 duodenal ulcer and nine jejunal ulcer patients.

Of the 184 cases operated upon two died in the immediate post-operative period, both from intestinal obstruction. One was a case of malrotation of the gut and death was from massive volvulus, while in the second case the obstruction was due to old tuberculous adhesions around the terminal ileum. This mortality of just over I per cent. is similar to that reported in many series.

\section{Duodenal Ulcers}

Of the 175 duodenal ulcer patients, six are excluded from the series as their letters were returned undelivered, while seven further patients failed to reply, so that a 92.5 per cent. follow-up was obtained ( 162 cases). Seven patients have died since their operations from causes unrelated to their peptic ulcers or their operation but unfortunately none were submitted to post-mortem examination. Two patients are in sanatoria and so are not subjected to conditions where their ulcers might be troublesome. There were two operative deaths. These I I cases are excluded from the follow-up. Thus ${ }^{1}{ }^{1}$ cases ( 86 per cent.) of duodenal ulcers are reviewed.

The results were classified into good, improved and bad categories. The good results were those in which there were no complaints and the patients were satisfied with the operation. In the improved cases were included those who, although able to work and getting no pain or indigestion, complained of symptoms that prevented them from forgetting about their stomach completely. The bad results were where the ulcer pain had persisted, further operations had been required or 
where it was found impossible to lead a normal life as a result of abdominal symptoms.

\begin{tabular}{|c|c|c|c|c|}
\hline & I 949 & $195^{\circ}$ & I95I & Total \\
\hline $\begin{array}{l}\text { Total } \\
\text { Good }\end{array}$ & $\begin{array}{l}65 \\
5381.5 \%\end{array}$ & $\begin{array}{l}53 \\
4788.7 \%\end{array}$ & $\begin{array}{l}33 \\
3090.9 \%\end{array}$ & $\begin{array}{l}\text { I } 51 \\
\text { I } 3086.1 \%\end{array}$ \\
\hline $\begin{array}{l}\text { Improved } \\
\text { Bad }\end{array}$ & $\begin{array}{l}913.9 \% \\
3 \quad 4.6 \%\end{array}$ & $\begin{array}{ll}2 & 3.8 \% \\
4 & 7.5 \%\end{array}$ & $\begin{array}{ll}1 & 3 \% \\
2 & 6.1 \%\end{array}$ & $\begin{array}{rl}12 & 7.9 \% \\
9 & 6 \%\end{array}$ \\
\hline
\end{tabular}

In reviewing this series it is important to compare the results with those of duodenal ulcers treated by gastroenterostomy alone. Clark (I95I) in his follow-up of over 300 gastroenterostomy cases traced for $I_{5}$ to 20 years, found that the great majority of anastomotic ulcers occurred in the first three years and after about ten years those cases that were symptom free almost always remained well. Classifying his cases in a similar manner to ours, his results are: Good, 68 per cent. ; improved, 9 per cent.; bad, 23 per cent.

Cooper (1948), in a ten-year follow-up of 257 duodenal ulcers treated by gastroenterostomy alone, found that the poor results were practically always due to a jejunal ulcer and that an active duodenal ulcer in the presence of a functioning stoma was very rare. In the 49 failures (I9 per cent.) of his series, jejunal ulcers were definitely present in 37 and probably present in a further 12 ; 47 of the failures occurred in the first five years and 13 of them settled with medical care and were finally classified as good results.

In our series time will show if the steady upward trend in the good result percentage is due to improving surgery or whether the jejunal ulcers have not yet developed in the later cases. While these late results in the treatment of duodenal ulcers by vagotomy and gastroenterostomy can be compared favourably with those after other forms of treatment, the percentage of failures is still high.

A comparison of pre-operative findings and the post-operative results shows that some slight selection of patients suitable for vagotomy is possible. In the pre-operative investigation of a case of duodenal ulcer, certain features can be determined: Age, length of history, presence of pyloric stenosis, sex, history of haematemeses and the results of the fractional test meal.

Age. Surgeons have always been chary of operating upon the younger patient with a duodenal ulcer with the result that many young men have been forced to lead unnaturally quiet lives until, after ten years or more, an operation has returned them to a normal life. In this series age had little bearing on the likelihood of a good result ensuing.

$\begin{array}{lcccc}\text { Age } & \text { Total } & \text { Good } & \text { Improved } & \text { Bad } \\ \text { Under 40 } & \mathbf{5 7} & 4986 \% & 47 \% & \mathbf{4} 7 \% \\ \text { Over 40 } & \mathbf{8 8} & \mathbf{7 5} 85.2 \% & \mathbf{6} 6.8 \% & \mathbf{7} 8 \% \\ \text { Over 60 } & 6 & 583.3 \% & \text { I } 16.7 \% & 0\end{array}$

Length of history. Similarly the duration of the disease does not affect the result. Both the findings are unlike those seen after gastroenterostomy alone, where the results improve the olde: the patient and the longer the history.

\begin{tabular}{|c|c|c|c|}
\hline $\begin{array}{l}\text { History } \\
\text { Under } 5 \text { years } \\
5 \text { to } 10 \text { years } \\
\text { Over Io years }\end{array}$ & $\begin{array}{c}\text { Total } \\
40 \\
42 \\
69\end{array}$ & $\begin{array}{c}\text { Good } \\
3690 \% \\
3583.3 \% \\
5985.5 \%\end{array}$ & $\begin{array}{cc}\text { Improved } \\
1 & 2.5 \% \\
7 & 16.7 \% \\
4 & 3.8 \%\end{array}$ \\
\hline
\end{tabular}

Pyloric stenosis. This has long been known give excellent results with gastroenterostomy along the poor results usually being in those cases whete the obstruction is due merely to temporary oedema around the ulcer: If the pyloric stenosis 왕 diagnosed only on the clinical history of vomitis of large quantities of food, the presence of visible peristalsis or the operative finding of a dilate stomach with a hypertrophied wall, the resulyz with gastroenterostomy alone are excellent. The addition of a vagotomy does not appear to affect the result in these cases.

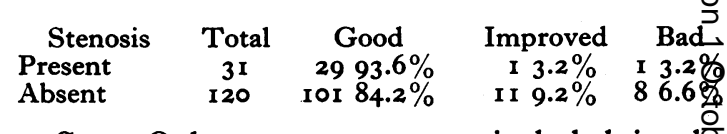

Sex. Only 14 women were included in series, an incidence of 9 per cent. All had good results from the operation and although oths number is too small to be of significance this. Is similar to the results after gastroenterostom alone, where women are found to be less liable tro have severe relapses.

Previous haematemeses. Haematemeses of ins sufficient severity to require immediate operation had occurred in I I of our cases, of whom sever have obtained good results, two are improved ang two are bad results. In none had there been any further haemorrhages but the number of cases too small to carry any statistical significance.

Test meal results. From the test meal two par ticular points were determined; firstly the pres sence of a hyperchlorhydria and secondly the level of the resting acid; it was felt that the latter was the important reading in the test meal as it gave some indication of the level of acidity which bathed the duodenum in the hours between meals while the hyperacidity at meals is at least on temporary and is buffered by the food. Un fortunately in only 70 cases was a test meal pere formed pre-operatively but no significant differenge could be demonstrated in the results achieved ing the different groups of gastric acidity.

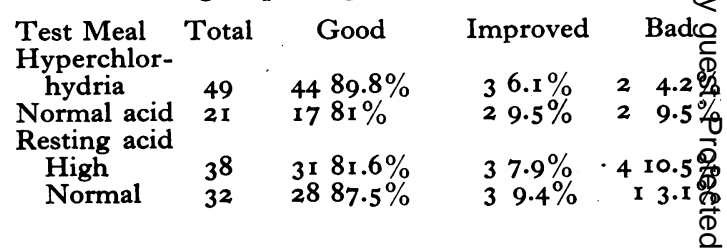




\section{A new book for the}

\section{OPHThalmology}

\section{A TEXTBOOK FOR DIPLOMA STUDENTS}

\section{by P. D. TREVOR-ROPER}

M.B., B.Chir.(Camb.), F.R.C.S., D.O.M.S.(Eng.)

Curator, Dept. of Pathology, Institute of Ophthalmology;

Asst. Ophthalmic Surgeon, Westminster Hospital.

This textbook aims to cover the field of ophthalmology required by the postgraduate student seeking an ophthalmic diploma. It deals at appropriate length, and in considerable detail, with the anatomy and physiology of the eye, with physical and physiological optics including the prescription of spectacles, and then covers systematically the diseases of the outer and inner eye. The emphasis falls throughout on clinical experience.

\section{$A$ new book for the \\ Studies on THe Cerebral Cortex}

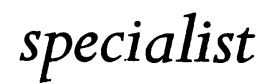

\section{by S. RAMÓN Y CAJAL}

(Translation from the Spanish by Lisbeth M. Kraft, Yale University.)

The timeliness of this translation is self-evident from the widespread and growing interest in the limbic system. Nevertheless, a precise knowledge of anatomy is essential to a thorough elucidation of function. When Ramón y Cajal undertook and completed the series of studies included in this volume he probably gave us the most precise and comprehensive single anatomical account of the limbic system that is available.

$x i i+179 p p$ 108 illustrations (1955) 27s. 6d. net

Descriptive leaflets available on request

\section{LLOYD-LUKE (MEDICAL BOOKS) LTD., 49 Newman Street,}

Thus in the pre-operative selection of cases, while pyloric stenosis patients and women are more liable to get a good result, youth and a short history do not contra-indicate the operation. The only other pre-operative test that might be of use is the night secretion volume and acidity but this was not performed in our series. Vagotomy might be found to give better results in those patients with a high level of night secretion, where presumably the vagal tone is high, than in those with a normal level, thus giving a useful pre-operative method of selection of cases.

In the post-operative examination complete vagal section is the main factor in determining the prognosis and the only means for deciding if this has been accomplished is the insulin test. It has been found that in the presence of hypoglycaemia overactivity of the vagal centre in the hypothalamus occurs with an increased secretion of gastric acid. The test is performed on the resting stomach, the resting gastric juice acidity and the fasting blood sugar are estimated, after which 15 units of soluble insulin are injected intravenously. Any rise in the gastric acidity is taken to indicate that vagal impulses are reaching the stomach. It has been found that to stimulate the hypothalamus the blood sugar must fall rapidly to below $40 \mathrm{mgm}$. per cent, and even then 6 per cent. of the pre-operative cases fail to show any rise in gastric acid. The test is purely qualitative and a positive result gives no indication of the number of vagal fibres that $\stackrel{0}{\circ}$ are stimulating the stomach. A negative result is $\stackrel{\unrhd}{\Omega}$ also difficult to evaluate as the tube may not have $\overrightarrow{\vec{O}}$ been in the stomach or the patient may be one of $\frac{0}{3}$ the 6 per cent. who give a false negative unless a pre-operative test has excluded these patients. Finally the test is not without discomfort to the patient.

In our series the insulin test was performed upon 74 cases and in these a rise in acidity occurred in 25 per cent.; thus it appears that in at least a 0 quarter of our cases vagal section was incomplete. $₹$ Repeated insulin tests on a few patients during the 윽 years of the follow-up showed that negative tests $>$ remained negative and that a test done in the immediate post-operative period was quite reliable; this also indicated that no vagal regenera- os tion had occurred.

In comparing the results in those cases where vagal section was incomplete with those where the 0 insulin test appeared to show that the vagotomy 0 was complete, the results are definitely better in the latter group. Many cases in which the section $\stackrel{?}{+}$ was incomplete, however, give excellent results and $\square$ this is to be expected in a test that is qualitative rather than quantitative as in all cases a very 
careful vagal dissection had been performed and presumably only a few small nerves had been left in most patients.

\begin{tabular}{|c|c|c|c|}
\hline $\begin{array}{l}\text { ny } \\
\text { te }\end{array}$ & $\begin{array}{c}\text { Total } \\
5574.3 \% \\
\text { I } 925.6 \%\end{array}$ & $\begin{array}{c}\text { Good } \\
5090.9 \% \\
\text { I } 368.4 \%\end{array}$ & $\begin{array}{c}\text { Improved } \\
3 \quad 5.5 \% \\
526.3 \%\end{array}$ \\
\hline
\end{tabular}

In the two bad results in the group where vagal section appears to be complete, both required further operation for recurrence of their original abdominal pain. In both their duodenal ulcers had healed and while in one no abnormality was discovered at operation, in the other a hypertrophic gastritis, noted at the time of his first operation, was still present and unchanged and was the probable cause of the symptoms. Neither of these patients was improved by their second operation.

In the bad result patient, whose vagotomy was incomplete, a large jejunal ulcer was found at his subsequent operation and this was treated by a partial gastrectomy; since that time he has been very well. This patient was operated upon by an assistant and was his only case in the series; vagal section was probably very incomplete and this was really a duodenal ulcer treated by simple gastroenterostomy. The poorer results in cases treated by surgeons with only a small series has been noted by Jordan (1952).

The only other test that might be of use in determining if the vagal section has been complete, is the post-operative night secretion estimation. This test was not performed in our series as it was felt that the results would be untrustworthy due to the gastroenterostomy and the reduced gastric tone and mobility; both of which would affect the amount of the gastric aspirate. However in a total vagotomy resting gastric section would be practically negligible, while the amount of secretion in the other cases might give some indication of the degree of vagal section.

Thus in the post-operative determination of the prognosis, the insulin test is the main factor available but if the operation has been performed thoroughly, even if the vagotomy is incomplete, a high proportion of good results will be achieved.

The bad results. Nine patients received bad results from their operation and in four of these a second operation was performed. As already mentioned, in one a large jejunal ulcer was found and in another a hypertrophic gastritis had failed to subside, but in all four cases the original duodenal ulcer had healed. In the other two of the four operation cases no abnormality was discovered. In the five patients who have not had any further operative treatment the original duodenal ulcer appears to be active in one but in the other four cases no cause can be found to account for their symptoms. Thus out of the nine气 failures, in six there is no obvious abnormality despite thorough investigation. The symptoms of which they complain include nausea and vomiting, indigestion and typical ulcer pain. Probably $\overrightarrow{\vec{\rho}}$ these symptoms are largely the result of faultyo mechanics due to the loss of tone and motility of $\frac{}{0}$ the stomach with imperfect emptying and sub- $\overline{\frac{\bar{s}}{2}}$ sequent gastritis. The appearance of a gastritis $\mathbb{\infty}$ is very difficult to be certain about and may easily be missed at laparotomy or on examination of $a^{\infty}$ partial gastrectomy specimen. The two patients $\vec{O}$ with negative laparotomies received no benefit $\overrightarrow{-}$ from their partial gastrectomies and possibly even $\omega_{\sigma}$ after resection stasis might still occur in the atonic stomach and prevent relief of symptoms. Barium 3 studies in the six idiopathic bad results, however, failed to demonstrate any very marked gastric $\vec{\omega}$ stasis, so as yet the cause of these failures is 0 undetermined.

The improved cases. Most of the symptoms here again appeared to be due to mild mechanical 을 defects as a result of the reduced gastric tone. The commonest trouble was a feeling of distension $O$ after meals with flatulence and belching; other complaints were very similar to the post-gastre 6 tomy dumping syndrome, with faintness and sweating after large meals necessitating the patief $\vec{f}$ lying down. In most of this group of patients symptoms appeared to be getting less frequerif possibly as a result of recovery of gastric tone, avoidance of large meals and by gastric hypertrophy overcoming any mechanical obstruction.

The good results. These were remarkable for $\frac{\circ}{\not}$ the excellence of their results, the immediate post-operative relief of their symptoms and the $\frac{0}{3}$ rapid increase in well-being. Most patients had a good appetite and enjoyed large meals and a full life. Many had put on weight and formed a marked contrast to the successful partial gastrec- $\frac{0}{3}$ tomy cases where often, although free from all pain and indigestion, only small meals can be 3 . taken, the appetite is poor or cannot be assuaged without discomfort and the patients fail to put on weight for many years. None of our cases com-o plained of diarrhoea although many said that their? bowels were improved and that they resorted to $\frac{D}{0}$ laxatives less frequently.

In comparing the results after vagotomy and $N$ gastroenterostomy with those after partial gastrec- $N$ tomy, three main features are available for comparison; the mortality, the recurrence of ${ }_{\sigma}^{\omega}$ ulceration and the associated effects of the operation. The mortality in the best centres for partial gastrectomy is rarely under 3 per cent. and is much higher throughout the country; for vagotomy and gastroenterostomy a mortality of about I per cent. as in this series is about that to be expected, $\mathbb{D}$ 
while large series without any deaths are recorded (Dragstedt, 1950). The incidence of recurrent ulceration after partial gastrectomy is low, probably in the region of 3 per cent. in the centres where a high resection is performed but higher after the more average resections performed elsewhere. In our series the bad results formed 6 per cent. of the cases although, as explained, only one of these was due to a jejunal ulcer. Among the associated effects the ability of the patient to enjoy his life, work hard and be really fit must be taken into account as well as the minor annoying features such as post-prandial distention and the dumping syndrome. One of the most satisfactory features of our series was the general well-being of the patients and this, together with the lower mortality and the nearly comparable percentage of good results makes the comparison of the two operations more equal.

\section{Gastrojejunal Ulcers}

Treatment of this type of peptic ulcer remains the one popular indication for the operation; good results are reported by numerous authorities (Orr and Johnson, I949) and the effects are considered by others to be superior to repeated resection in those cases that follow partial gastrectomy (Walters, 1955). It is this fact that makes it difficult to understand the poor regard for the operation in the treatment of duodenal ulcers. If, as is generally admitted, the main failing of gastroenterostomy for duodenal ulcers is the high incidence of jejunal ulcers and if the latter are believed to be cured by vagotomy, it is reasonable to assume that associating the gastroenterostomy with a vagotomy will prevent the formation of jejunal ulcers and cure the duodenal ulcers.

In discussing jejunal ulcers two main varieties must be considered, those following gastroenterostomy and those after partial gastrectomy. After partial gastrectomy they rarely occur unless the original lesion was a duodenal ulcer; after gastroenterostomy they are less common in the presence of pyloric stenosis, in elderly patients or if there is a long history of ulceration, all conditions where the acidity tends to be lowered. Nearly always the ulcer occurs in the efferent loop of the jejunum or on the line of the anastomosis and is usually quite small, only about $5^{\circ}$ per cent. being demonstrable on barium studies.

In our series there were only seven jejunal ulcers and all followed gastroenterostomy for duodenal ulcers; their second operations occurring one to nineteen years later, averaging six years. Six were treated by simple vagotomy and four of these have remained very well since their operations five years ago; the seventh had his vagotomy combined with re-doing of the gastroenterostomy and has also been very well for five years. Of the other two, one began to develop obstructive symptoms after six months and at a further operation the jejunal ulcer was healed but in healing had obstructed the stoma; since partial gastrectomy he has been very well. The other case originally had a gastroenterostomy in 1943 followed, in 1947 , by an enteroanastomosis and developed a jejunal ulcer which was treated by vagotomy in 1949; however his jejunal ulcer failed to heal and a year later he had a partial gastrectomy, since when he has been very well. The association of the enteroanastomosis with a gastroenterostomy carries a high risk of jejunal ulceration and is almost comparable with the Mann-Williamson operation in dogs. Maybe the presence of this enteroanastomosis explains the failure of the ulcer to heal, but in this one case the vagotomy was also incomplete as shown by the insulin test. No cases of jejunal ulcer following partial gastrectomy were treated in this series.

Two cases of gastrojejuno-colic fistulae were treated, both following gastroenterostomy for duodenal ulcer. The first had his original operation in 1929 and reported in a poor general condition in $195^{\circ}$ after a year's diarrhoea; at operatio he had a very large jejunal ulcer with a large fistula into the colon, vagotomy was performed, the gastroenterostomy undone and a new one mader. A catheter was placed in the fistula into the colon and brought out of the lower end of the wound; this fistula discharged very little and healed spontaneously. Since that time he has been very well.

The second case had his gastroenterostomy in r944 and developed a jejunal ulcer in 1948; this was followed in two months by loss of his pain and onset of diarrhoea and foul eructations. He was treated by vagotomy and division of the fistula into the colon, which was drained by a catheter; the gastroenterostomy was left. Post-operatively he was very well but unfortunately died four years later of carcinoma of the larynx.

These results for jejunal ulcers seem to confirm the general opinion that vagotomy will heal the ulcer, but fibrous obstruction in a small number of cases suggests that: the larger ulcers should be associated with undoing of the original anasto- $N$ mosis and formation of a new stoma; undoubtedly closure of the stoma is inadequate as the resultant $\mathcal{O}$ gastric stasis will produce the undesirable effects $\omega$ of simple vagotomy. The excellent results of this simple treatment of gastrojejuno-colic fistula is also of importance, as usually these patients are in a parlous condition and the major operation of : gastric and colonic resection often advised carries a high mortality.

Bibliography on page 537 
possibility of necrosis and autodigestion in an aberrant pancreas producing a cyst in which no trace of the original lesion could be found.

(d) Cyst of Brunner's glands. Robertson (I94I) mentioned the possibility of a retention cyst of Brunner's glands but stated that these cysts were usually only a few millimetres in diameter and were symptomless. Booher and Pack (1946) reported a case of cystic tumour of duodenum of this nature in a female aged 52.

Adenoma of Brunner's glands are rare. They present with haemorrhage or obstruction. Feyrter (1934) found three in 2,800 duodena examined. Cases have been reported by Willis and Lasersohn (1925) and Balfour and Henderson (1929). These adenomata may undergo cystic degeneration. There was no histological evidence of this in our specimen.

(e) Lymphatic cyst arising in the submucosal lymphatics. Lymphatic cysts are not uncommon in the mesentery of the small intestine. We have not been able to trace any case of submucosal lymphatic cyst in the literature.

The only similar case of duodenal cyst in the literature was reported by Riker (I95I). In discussing the probable aetiology he mentioned the possibility of a duodenal cyst being the result of a tiny mucosal perforation with abscess formation and organization of haematoma from spontaneous submucosal haemorrhage.

From the histology it is evident that this cyst had been present for some time. Haemorrhage occurred into it probably at the time of the eclamptic fits. This would account for the rather marked fall in blood pressure which succeeded the convulsions, the early appearance of anaemia, the pain and tenderness in the upper abdomen which we had regarded as hepatic in origin, the slight jaundice and especially the incomplete duodenal obstruction which was such a dominant feature of the case.

Treatment of duodenal cysts is on the whole extremely unsatisfactory. One reason for this is that they usually occur in infants who, because of prolonged vomiting, are poor operative risks. Mortality in infants is as high as 70 per cent. (Gordimer and Bluestone, 1950), but it is lower in adults. In no case in the literature has duodenectomy been performed for this benign condition.

\section{Summary}

A case of post eclamptic anuria complicated by duodenal obstruction due to haemorrhage into a duodenal cyst is described. The difficulties encountered in the management of the case are discussed. A review of the literature on duodenal cysts is given.

\section{Acknowledgment}

We wish to thank Sister M. H. Crandall, के S.R.N., S.C.M.; Mr. R. J. Edwards, Drs. G. $\vec{\circ}$ Bras and W. R. Cole of the Departments of Medicine, Pathology and Radiology for their co- $\vec{\omega}$ operation; and Professors D. B. Stewart and G. H. C. Ovens for their advice and encouragement.

\section{BIBLIOGRAPHY}

BALFOUR, D. C., and HENDERSON, E. F. (1929), Ann. Surg., O

BLACK, D. A. H., and PYRAH, L. N. (1954), Proc. Roy. Soc. ज़ Med., 47, 582 .

BOOHER, R. J., and PACK, G. T. (1946), Arch. Surg., 53, 588. BROOKS, B., and WEINSTEIN, A. (1943), Ibid., $117,728$. BULL, G. M., JOEKES, A. M., and LOWE, K. G. (1949), Lancet, ii, 229.

CHALMERS, J. A., and FAWNS, H. T. (1955), Ibid., i, 79.

FEYRTER, F. (1934), Virchows Arch. f. Path. Anat., 293, 509, quoted by H. E. ROBERTSON.

GAMBLE, J. L. (1947) ' Extracellular Fluid,' 5th edition, Harvard University Press. Massachusetts,

GARDNER, C. E., and HART, D. (1935), f. Amer. med. AsEु I04, 1809 .

GORDIMER, H., and BLUESTONE, L. (1950), Ann. Surg I32, 1149.

HILDES, J. A., and FERGUSON, M. H. (1952), Gastroenterology 2I, 64.

HOWARD, J. E., and CAREY, R. A. (1950), F. Clin. Endocrinol., 9, 69r.

LORBER, S. H., and MACHELIA, T. E. (1948), Gastroenterology, TO, 892.

NEWMAN, E. A., and EISENSTEIN, M. (1949), Ibid., 13, 528. NORRIS, J. C. (1946), South med. F., 39, 549.

PEPLE, W. L. (1948), Ann. Surg., 127, 912.

POLSON, R. A., and ISSAC, J. E. (1953), Gastroenterology, 25, $43 \mathrm{I}$.

RIKER, W. L. (I95I), Amer. F. Surg., 81, 464.

ROBERTSON, H. E. (1941), Arch. of Path., 31, 112.

ROTH, M. (1881), Virchows Arch. f. Path. Anat., 86, 371, quoted by C. E. GARDNER and D. HART.

RUSSELL, C. S., DEWHURST, C. J., and BRACE, J. C. (1954), Lancet, $i, 902$.

SANGER, M., and KLOPP, A. (1880), Arch. f. Gynak.; 16; 415, quoted by C. E. GARDNER and D. HART.

SHALLOW, T. A., WAGNER, F. B., and MANGES, W. B. (1947), Surg., 21, 532.

WARREN, K. W. (1951), Surg. Clin. N. America, 31, 789.

WHEELER, W. I. DE C. (1940), Brit. F. Surg., 27, 446:

WHIPPLE, A. O. (1950), ("Non-ulcerative lesions of the duo- $\frac{I}{O}$ denum,' by Frederick Christopher), 'Textbook of Surgery,' 5 th edition, W. B. Saunders Co., Philadelphia.

WILLIS, A. M., and LASERSOHN, M. (1925), Ann. Surg., 82, N 952.

Bibliography continued from page 515-B. V. McEvedy, F.R.C.S., and G. K. Kirkland, M.B., Ch.B., D.P.H. BIBLIOGRAPHY

CLARK, D. H. (1951), Brit. med. F., i, 57.

COOPER, W. A. (1948), Surgery, 23, 425.

DRAGSTEDT, L. R., et al. (1947), Ann. Surg., 126, 687.

DRAGSTEDT, L. R. (1950), Ibid., 132, 626.

JORDAN, S. M. (1952), Gastro-Ent., 22, 295.

ORR, I., and JOHNSON, H. D. (1949), Brit. med. F., ii, 1316.

WALTERS, W., et al. (1955), Surg. Gyn. and Obstet., 100," 